\title{
Levantamentos territoriais e construção de saberes geográficos na Comissão de Linhas Telegráficas Estratégicas do Mato Grosso ao Amazonas (1907-1915)
}

\author{
Territorial surveys and formation of geographical knowledge in Strategic \\ Telegraph Commission of Mato Grosso to the Amazon (1907-1915)
}

PATRICIA MARINHO ARANHA

Casa de Oswaldo Cruz | Fiocruz

\begin{abstract}
RESUMO Este artigo tem por objetivo analisar os trabalhos de levantamento territorial e inventário do território noroeste do país realizados por engenheiros militares da Comissão de Linhas Telegráficas Estratégicas do Mato Grosso ao Amazonas. As atividades desenvolvidas por estes militares no interior da Comissão estavam diretamente relacionadas a incursões que visavam o conhecimento dos principais rios da região e seus afluentes, determinando assim a possibilidade de seu uso para a penetração territorial. Os diferentes saberes geográficos produzidos na prática, por meio da atuação dos engenheiros, são o principal objeto de análise.
\end{abstract}

Palavras-chave Comissão Rondon - engenheiros militares - território - saberes geográficos.

\begin{abstract}
The present article aims to analyze the works of land survey and inventory of the northwest territory of the country carried out by military engineers from the Strategic Telegraph Commission of Mato Grosso to the Amazon. Available information show that the activities developed by these military within the Commission were straightly connected to raids that were aiming for the knowledge of the main rivers of the region and their tributaries, determining so the possibility of their use for the territorial penetration. The goal is to show an analysis from different geographic knowledge, produced in practice, through the performance of these military engineers.
\end{abstract}

Key words Rondon Commission - military engineers - territory - geographical knowledge.

\section{Introdução}

Nos primeiros anos do século XX, com a recém-instituída República brasileira, o Estado se voltava para seu território. Conhecer suas riquezas, população, integrá-lo e ocupá-lo eram as premissas do novo governo. ${ }^{1}$ Neste contexto, com 0 debate acerca da integração nacional ganhando força, Mato Grosso, Amazonas e Acre se destacavam como principais alvos de iniciativas com este objetivo. Estes estados eram muito desconectados da então Capital Federal, o Rio de Janeiro, e havia dificuldade até mesmo em relação aos caminhos para se chegar até eles. À época o modo mais fácil de empreender a viagem era através de um longo percurso fluvial atravessando outros países, como Argentina, 
Uruguai e Paraguai, para então se chegar ao Mato Grosso. Os poucos caminhos terrestres existentes eram penosos e pouco transitáveis em determinadas épocas do ano, como entre os meses de dezembro e maio, por exemplo, quando acontece a cheia dos rios. ${ }^{2}$

Para incorporação efetiva e defesa dessas regiões, parecia premente o conhecimento desta parte do território do país. A partir desta discussão um projeto político de integração territorial começou a ser pensado. Desta forma, foram organizadas pelo Estado brasileiro várias viagens científicas e comissões de exploração. Entre estas iniciativas do Estado estão: as viagens do Instituto Oswaldo Cruz (realizadas nas duas primeiras décadas do século XX), a Comissão Construtora de Linhas Telegráficas de Goiás a Mato Grosso - Comissão de Goiás (1891/1898), a Comissão Construtora de Linhas Telegráficas do Mato Grosso - Comissão do Mato Grosso (1900/1906), e a campanha de Rondon na Comissão de Linhas Telegráficas Estratégicas do Mato Grosso ao Amazonas - a CLTEMTA (1907-1915), por exemplo. Devido ao papel central de Cândido Mariano da Silva Rondon e por sua importância quase mítica, são comumente chamados de "Comissão Rondon" todos os trabalhos por ele realizados no interior do país durante sua carreira militar, que foi do ano de 1889 a 1939. Neste artigo, por Comissão Rondon me refiro, especificamente, à CLTEMTA.

Neste sentido, os inventos técnicos eram tidos como cruciais para agilizar as comunicações e incentivar a ocupação destas áreas. Seguindo as expectativas da época, o telégrafo seria um precursor da civilização, do desenvolvimento material do território, da integração e da promoção de uma cultura nacional. ${ }^{3}$ Contudo, seu estabelecimento não viria sozinho; no que refere especificamente às comissões construtoras de linhas telegráficas, a preocupação do Estado brasileiro não se resumia a estabelecer as comunicações com os territórios ao noroeste do país, mas "encerrar os principais pontos do país, de forma a permitir a integração e vigilância". ${ }^{4}$

Por este motivo, a CLTEMTA possuía, como seu próprio nome já expressa, valor estratégico e crucial para a incorporação, ocupação e conhecimento da porção noroeste do território brasileiro. Este empreendimento uniu às atividades de instalação do telégrafo serviços de exploração territorial, demarcação, proteção de fronteiras e levantamento científico de recursos naturais. Sendo assim, esta não foi somente uma comissão telegráfica, mas antes uma instituição científica. Independentemente de seu caráter provisório, ela funcionou como um espaço de produção e fomento da ciência no Brasil, com papel crucial na própria institucionalização das ciências no país. ${ }^{5}$ Estes objetivos científicos estavam diretamente ligados ao estabelecimento de infraestrutura em comunicações, esperando-se que, juntos, telégrafo e ciência cumprissem a meta de modernização e integração efetiva do território nacional.

Dentre as atividades desenvolvidas na Comissão, a que destaco neste artigo são as relacionadas aos saberes geográficos: ${ }^{6}$ levantamento topográfico, demarcação de fronteiras, correção de mapas, levantamento de rios e seus afluentes realizadas por engenheiros militares do Exército. Os saberes geográficos se construiriam na prática, se revelando através dos produtos do trabalho destes engenheiros.?

\section{Modernização e incorporação: as incursões territoriais}

0 principal objetivo da Comissão era conhecer, integrar, aproximar espaços tidos como afastados e atrasados e transformá-los em áreas produtivas, preparando-as para uma ocupação que deveria ir à esteira das melhorias da infraestrutura local. 0 conhecimento destes territórios seria pautado por levantamentos de cunho geográfico se valendo de rios como caminhos. ${ }^{8} 0$ telégrafo viria acompanhando, atravessando e margeando importantes rios da região, entre eles o Madeira e o Juruena, por exemplo.

0 planejamento era ampliar a linha já existente entre o Rio de Janeiro e o Mato Grosso. De Cuiabá, o telégrafo iria até Santo Antônio do Madeira; além desta linha principal, chamada linha tronco, mais três ramais deveriam ser construídos: para o Acre, Purus e Juruá, ficando a cargo da Comissão a escolha do ponto a partir do qual a linha seria estendida até Manaus. Os pontos extremos da linha seriam Cuiabá, Santo Antônio do Madeira e Manaus. 
A construção do telégrafo em meio à floresta dependia diretamente dos reconhecimentos territoriais, pois eles eram imprescindíveis para o próprio avanço da construção da linha telegráfica. De acordo com as determinações presentes nas Instruções de criação da Comissão, as explorações comandadas pelos engenheiros militares determinariam o melhor traçado para o telégrafo, o caminho mais simples a ser tomado para adentrar a floresta, quais rios poderiam ser utilizados para escoamento de produção bem como a identificação de áreas que se adaptariam à agricultura ou pecuária.

Com o desenvolvimento do noroeste do país através do telégrafo, o governo brasileiro esperava uma grande quantidade de migrantes que se destinariam às terras do Mato Grosso e do Amazonas. De acordo com o planejamento do Estado, o estabelecimento de infraestrutura em comunicações através do telégrafo constituiria um cenário de apoio às populações que já habitavam estas áreas e um incentivo ao seu maior povoamento. ${ }^{9}$ Assim, a CLTEMTA agiria em três frentes, o incentivo ao povoamento, 0 conhecimento do território com vistas a sua proteção e 0 apoio ao desenvolvimento de atividades produtivas na região. Estes objetivos centrais estavam intrinsecamente ligados, pois do desenvolvimento e diversificação de atividades produtivas dependia o afluxo populacional esperado, e da sua ocupação, a proteção da região.

A diversidade nos objetivos da Comissão se dava, principalmente, devido a sua tripla filiação ministerial. Ela estava subordinada, concomitantemente, a três Ministérios: ao Ministério da Guerra, da Agricultura e da Viação e Obras Públicas. ${ }^{10} 0$ Ministério da Agricultura almejava o conhecimento de novas áreas disponíveis para a lavoura ou que pudessem ser destinadas a pastagens de gado. Já o Ministério da Viação e Obras Públicas tinha interesse na comunicação via telégrafo e na construção de estradas de rodagem que acompanhariam as linhas; também no conhecimento de rios com objetivos ligados ao transporte, ao uso dos rios como caminhos e estradas. ${ }^{11} 0$ Ministério da Guerra fornecia os oficiais engenheiros formados nas escolas do Exército - Escola Militar do Brasil e Escola de Artilharia e Engenharia, além de praças que se dedicariam ao trabalho mais pesado de construção de linhas telegráficas, como a abertura de piques na mata e a confecção dos postes.

A Rondon e seus subordinados era delegada a tarefa de enviar a estes Ministérios relatórios detalhados acerca da exploração das áreas e do andamento da execução das linhas e abertura de estradas. Estes relatórios tinham por objetivo 0 esclarecimento acerca do território explorado, como uma espécie de inventário. ${ }^{12}$

A Comissão possuía então múltiplos papéis e objetivos, unia a instalação do telégrafo à exploração territorial. A incorporação destas áreas dependia diretamente do conhecimento que sobre elas havia, sendo preciso explorar e mapear para que a região se tornasse acessível. Por este motivo as atividades ligadas a incursões territoriais possuem grande destaque nos relatórios da CLTEMTA. Neles há informações sobre as explorações empreendidas e cartografia, devendo este conhecimento ser a mola propulsora da incorporação, da ocupação e efetiva unidade física do Brasil.

Um dos aspectos mais importantes do plano de desenvolvimento da região noroeste do Brasil, proposto quando da criação da Comissão, reside no apoio que o telégrafo daria às atividades produtivas já desenvolvidas nesta área, sendo a principal delas a extração do látex para a fabricação da borracha. À época do início de seus trabalhos, no ano de 1907, a produção brasileira estava a pleno vapor, correspondendo à sexta parte da receita do Estado. ${ }^{13}$ Durante os anos em que funcionou, a CLTEMTA acompanhou o apogeu e a crise da economia da borracha. Assim, eram executados planos que permitissem a integração dos centros produtores ao restante do país e que fossem pensadas alternativas à produção exclusiva da borracha. Neste sentido, era premente tornar aqueles espaços atrativos para novos investimentos, 0 que colocava em pauta a importância dos inventos técnicos e trazia para primeiro plano 0 telégrafo. ${ }^{14}$

Desta forma, a Comissão representava a ponta de lança do Estado brasileiro para a modernização da região amazônica. Suas diferentes bases atenderiam aos diversos objetivos propostos quando de sua criação. 0 telégrafo se destacava como fator central para a manutenção e ampliação da população na região e o conhecimento destes territórios, sobretudo de seus rios, como alicerce para planos de circulação de pessoas e escoamento da produção local. ${ }^{15}$

A centralidade dos rios para o cumprimento dos objetivos da Comissão está expressa nas Instruções da Comissão e também nos relatórios dos engenheiros militares. Por conseguinte, a extensão do telégrafo na região da bacia do 
Amazonas estava diretamente ligada ao conhecimento dos rios daquelas localidades, estes eram usados como base e referência principal para o traçado que a linha deveria seguir. Juntos, telégrafo e rios serviriam ao plano de modernização da região noroeste do país. ${ }^{16}$

0 trabalho de exploração territorial e definição dos pontos onde seria instalado o telégrafo era executado por engenheiros militares do exército. Para a execução de suas atividades estes homens realizaram diversas viagens. As incursões deram origem a uma série de produtos, são eles: os já mencionados relatórios, as cadernetas de campo e os mapas. ${ }^{17}$

Os relatórios dos engenheiros da Comissão se constituem em um apanhado de informações colhidas em campo. Há, por exemplo, descrições das margens dos rios, da vegetação encontrada, das populações que habitavam as regiões estudadas, entre outras. As cadernetas formam uma compilação de informações coletadas durante a viagem, no calor da hora, geralmente possuindo uma parte destinada somente a croquis das áreas percorridas, o que servia de base para a produção de mapas. Os mapas eram o último produto do trabalho dos engenheiros, sendo feitos com base nas informações de relatórios e cadernetas.

Como elementos presentes nos relatórios, destaco a forte presença de discursos que apresentavam os territórios do interior do Brasil e reafirmavam a meta de "civilizar os sertões", de aproximar estes espaços, torná-los produtivos. Estes relatórios se constituem numa sistematização analítica de informações presentes nas cadernetas e, quanto à forma, estes documentos não obedecem a uma normatização regular. Alguns relatórios possuem tópicos com itens detalhados, tais como: despesas, trabalhos efetuados, a viagem para o território que deveria ser analisado, além de mapas e fotos, enquanto outros se resumem a um mapa ou uma descrição da viagem dia a dia.

Também não há uma regra na Comissão no que diz respeito às designações para cada engenheiro. Enquanto alguns estudavam um grande rio, ou um território de grandes proporções, outros poderiam estudar um afluente de rio ou uma pequena vila.

Quanto às cadernetas de campo, estas se subdividem nos seguintes grupos: reconhecimento, locação, levantamento, livro de postes e exploração. Contudo, não há linearidade acerca da produção das cadernetas, nem todas as expedições possuem cadernetas de todos os grupos elencados.

A exploração, a rigor, acontecia depois da locação e do levantamento, no entanto, na documentação da Comissão, há cadernetas de levantamento que, tamanho o detalhamento, apontam que 0 trabalho realizado era de exploração e, por isso, geraram relatórios de exploração. Ademais, a exploração poderia acontecer como uma única etapa, sem necessariamente haver outro tipo de caderneta, desde que esta fosse consequência de uma ordem para o reconhecimento de um rio ou região considerada estratégica.

Através da observação da tipologia estabelecida nas cadernetas, podemos dividir as etapas da incursão territorial da seguinte forma. ${ }^{18}$

Locação ou Reconhecimento: esta era a primeira atividade da incursão, onde eram analisados aspectos do território como a vegetação, a presença de rios, a configuração de suas margens, o tipo de solo e se havia ou não população já estabelecida. Também era analisado pelos engenheiros se a área poderia ser alvo de estudos com detalhamento maior, bem como a maneira pela qual estes seriam realizados - eles seriam possíveis através da navegação, ou da abertura de picadas, por exemplo.

Levantamento e Levantamento Expedito: o levantamento viria após a etapa de reconhecimento preliminar. Este tinha por objetivo estabelecer as bases para uma possível incursão posterior, fornecendo-lhe elementos gerais da área percorrida. 0 levantamento expedito era a forma menos precisa de estudo do território; nele nem sempre havia exatidão com relação aos dados coletados. Os principais instrumentos utilizados nesta etapa eram a bússola e a corrente. Através do uso de uma corrente estendida com determinado comprimento (de acordo com os relatórios elas mediam, em geral, 20 ou 40 metros) era possível determinar a extensão do percurso multiplicando o tamanho da corrente pelas vezes em que havia sido colocada no percurso, e com o uso da bússola, o rumo tomado. Também eram medidas as altitudes e as distâncias entre os principais pontos da área explorada (morros, cachoeiras e povoados eram considerados pontos 
de destaque). Assim, percebemos que, enquanto o Reconhecimento consistia numa etapa de observação de aspectos mais gerais do território percorrido, no Levantamento eram efetuadas medições da área atravessada, que serviriam de base, ainda que não completamente precisas, para uma futura exploração.

Exploração: nesta etapa, dados precisos do território percorrido eram coletados. Todos os aspectos da área a ser explorada eram analisados: sua vegetação, solos, aspectos do fundo do rio, cachoeiras, corredeiras, altitudes, populações, temperatura e fauna, todos faziam parte deste minucioso estudo. Dados topográficos mais precisos eram coletados fornecendo, assim, a possibilidade de preparação de cartas ou mapas das regiões que haviam sido exploradas. Defino, assim, esta parte do trabalho como uma espécie de raios $X$ do território analisado.

Retornando à tipologia das cadernetas da Comissão, a caderneta de livro de postes ou caderneta de postes tinha um caráter mais técnico: analisava a linha telegráfica, postes e emendas a fim de dar conta da conservação e funcionamento da mesma. Quanto à autoria, nem sempre o engenheiro responsável pela expedição é o autor das cadernetas; a maioria delas nem mesmo possui assinatura. As cadernetas também não se encontram divididas equitativamente de acordo com os relatórios: há relatórios feitos a partir de uma ou duas cadernetas, enquanto outros se valeram de mais de uma dezena delas.

A partir da apresentação das etapas da incursão territorial, passarei ao trabalho específico dos engenheiros durante suas expedições. As atividades desenvolvidas por estes militares, como venho afirmando, baseavam-se em dois eixos: no conhecimento do território, sobretudo dos rios, com vistas à funcionalidade na locomoção pela região amazônica, e no estabelecimento e conservação da linha telegráfica. Os engenheiros que destaco neste artigo são: Antonio Pyrineus de Souza, Emanuel Silvestre do Amarante e Manoel Teophilo da Costa Pinheiro. ${ }^{19}$ Estes engenheiros se ocuparam eminentemente de trabalhos de levantamento e exploração de rios.

As expedições comandadas por estes engenheiros me parecem de peculiar importância devido a alguns fatores, entre eles: a quantidade de cadernetas que geraram, o número de pessoas nelas envolvidas, bem como de sua visão estratégica para a ocupação e conhecimento do território. São elas: a do rio Jaru; a dos rios Papagaio, Juruena e Burity; e do rio Jacy-Paraná. ${ }^{20}$

\section{A construção dos saberes geográficos}

Nas viagens de levantamento territorial realizadas pelos engenheiros militares subordinados à Comissão foi-se construindo os saberes geográficos acerca daquelas regiões. Estes saberes podem ser divididos em três categorias: 0 relacionado ao inventário do território percorrido, o de apoio logístico à construção da linha telegráfica e o representacional - que encontra sua materialidade nos mapas.

Entretanto, é importante destacar que como ponto comum entre estes saberes geográficos está a forma de coleta de informações e apresentação. 0 conhecimento produzido por estes homens deveria ser utilitário, técnico, sua finalidade era dar suporte ao plano de modernização da região amazônica, sendo assim, os aspectos relatados possuíam um padrão de apresentação no formato de carta-itinerário. A intenção principal era revelar os caminhos percorridos, as dificuldades encontradas, o meio de transpô-las, elementos acerca da navegabilidade de rios e se estes ofereciam ou não problemas se fossem usados como caminhos. ${ }^{21}$

Até mesmo quando há informações acerca da vegetação das margens, dos produtos locais ou minerais encontrados, elas estão colocadas sob o ponto de vista de seu uso posterior. Saber onde havia barracões de seringa significava encontrar pouso ou comida em casos de extrema dificuldade, conhecer os cultivos de roçados locais era essencial para a promoção da futura ocupação destas áreas e conhecer os minerais presentes fazia parte do planejamento de exploração de todas as potencialidades locais, da diversificação da economia local. 
Desta forma, a partir dos diferentes tipos de saberes geográficos e observando os pontos de contato e distanciamento entre eles, abordarei as expedições selecionadas. A expedição do rio Jaru, realizada por Antonio Pyrineus de Souza no ano de 1909, é particularmente exemplar do saber de cunho representacional. 0 principal produto desta expedição não é um relato de viagem, mas um relatório-mapa dos mais minuciosos preparados pelos engenheiros militares da CLTEMTA. Como ponto de aproximação entre os diferentes saberes geográficos, no mapa aparecem com destaque barracões de seringa, serras ou pontos de maior altitude além dos afluentes do Jaru. Também são retratadas todas as corredeiras e cachoeiras da área por ele percorrida. A ênfase na identificação de todos os barracões de seringueiros estava relacionada à visão estratégica no momento de alta da economia baseada na extração do látex. Da mesma forma, representar todas as cachoeiras ou corredeiras encontradas era essencial neste contexto onde os rios eram vistos como caminhos essenciais nas incursões territoriais pela região noroeste do Brasil.

Fica claro que os objetivos da Comissão tinham importância na própria escolha de pontos representados. Barracões, estações telegráficas e comunidades indígenas, áreas de alta altitude, como serras, por exemplo, estão no mapa do rio Jaru. 0 discurso integrador presente nas Instruções da CLTEMTA também se construía no mapa, o rio e seus afluentes eram descritos com minúcia e de acordo com a possibilidade de seu uso para o transporte. Da mesma forma, também é possível analisar, a partir do mapa, que este vinha ao encontro das designações ministeriais. Quando mostrava onde estavam os barracões, as montanhas e as chapadas, seu autor informava às pastas da Viação e da Agricultura sobre a possibilidade de ocupação: das áreas que poderiam ser usadas para a extração do látex e para a implementação da agricultura, bem como da possibilidade do escoamento dos produtos da região. As representações cartográficas também vinham ao encontro dos objetivos estratégicos do Ministério da Guerra: este poderia ter informações precisas sobre os territórios próximos às fronteiras bem como sobre a maneira mais rápida de realizar uma incursão nos espaços já explorados.

Na viagem de Emanuel Silvestre do Amarante para a região entre os rios Papagaio, Burity e Juruena realizada em 1909 se desenvolveram dois tipos de saberes geográficos: o de apoio logístico, visto que parte da linha telegráfica acompanharia o rio Juruena até mesmo com construção da estação telegráfica do Juruena, e o relacionado ao inventário territorial. É interessante destacar que estes dois tipos de saberes são complementares, pois a descrição do território percorrido na forma de inventário era de crucial importância para determinar por onde seguiria a linha telegráfica, bem como para a análise da viabilidade do prosseguimento da construção da estrada de rodagem já existente entre Tapirapoã e 0 Juruena. Também se foi construindo o saber geográfico de inventário territorial durante a expedição de Manoel Teophilo da Costa Pinheiro para o rio Jacy-Paraná no ano de 1909. Esta expedição foi considerada particularmente estratégica pelo fato de o rio Jacy-Paraná ser um importante afluente do rio Madeira. Segundo consta nas Instruções, a bacia deste rio deveria ser detalhadamente analisada do ponto de vista de sua navegabilidade e da possibilidade do desenvolvimento de povoados em seu entorno.

Em ambos os relatórios há a presença maciça de informações acerca das dificuldades impostas pelo rio e de dados acerca das maneiras encontradas para enfrentá-las. Amarante afirma que, para atravessar um rio, foi preciso que se estendesse um arame de uma margem à outra devido a sua correnteza e grande volume d'água. Costa Pinheiro também relata suas dificuldades na subida do Jacy-Paraná, contudo estas se davam não pelo excesso de água, mas pela falta. Em determinado momento de sua expedição as águas do rio baixaram tanto a ponto de não haver nem mesmo um palmo d'água de profundidade, tornando a navegação impossível, o que fazia com que as canoas fossem arrastadas por vários quilômetros: "Assim fomos caminhando, de vez em quando no arrastão, passando dias inteiros quase dentro d'água até a cachoeira Criminosa, a primeira a começar da Fóz."22

Além do pouco volume de água, informações como o número de cachoeiras e seu tamanho também ganham destaque no relatório de Costa Pinheiro. São enumeradas tanto cachoeiras quanto corredeiras, bem como a maneira como foram contornadas, através da abertura de picadas pelas margens. Entretanto, as cachoeiras não representavam apenas um obstáculo, elas também poderiam ter valor estratégico para a produção de energia, por isso eram alvo da análise de seu possível valor industrial. 
Outra característica importante destacada pelos engenheiros é a constituição das margens dos rios. Amarante descreve que havia muitos brejos, ou o que chamou de mata brejosa, e novamente percebe-se a importância de informações sobre o itinerário e a maneira de percorrer o território pesquisado. Os percalços ao andamento da viagem eram importantes, pois diante da possibilidade de uma nova exploração, o novo grupo ficaria sabendo de antemão o que iria enfrentar e por quanto tempo. Da mesma forma, Costa Pinheiro descreve as margens do Jacy-Paraná como:

()constituição arenosa, pedregosa, argilo-arenosa e argilosa. Algumas vezes observa-se, nas altas barrancas, o barro vermelho e a tabatinga. A constituição do fundo do leito é, ou arenosa ou pedregosa; em alguns trechos nota-se, por sobre a camada arenosa, uma delgada camada argilosa; em outros, principalmente nas proximidades da foz, o fundo do leito é constituído por um cascalho muito miúdo ${ }^{23}$

Quanto à vegetação, um ponto em comum evidenciado nas viagens de Costa Pinheiro e Amarante é a seringueira. Barracões de borracha e propriedades de seringalistas são descritas desde seu posicionamento em relação ao rio até sua extensão e o número de trabalhadores empregados. A identificação dos barracões também era parte da estratégia de apoio às expedições da Comissão, uma vez que eles muitas vezes funcionavam como depósitos de suprimentos quando da passagem por um trecho do rio que não permitisse franca navegação. 0 depósito era uma forma comumente utilizada para estocar gêneros e levar menos peso às costas em caminhadas pela mata. Ainda em relação à vegetação, também era levado em conta o tipo encontrado durante o levantamento. Amarante descreve que os territórios por ele percorridos eram de cerrado, mata e mata alagadiça. Informações deste tipo são importantes, pois determinam de que lado do rio a incursão deveria seguir para, por exemplo, evitar a mata brejosa e seguir abrindo picadas pelo terreno seco.

Para finalizar, os povoados encontrados bem como comunidades indígenas estavam presentes nos relatórios e mapas. Pyrineus de Souza, Amarante e Costa Pinheiro destacam a localização geográfica destes pontos. Amarante e Costa Pinheiro também descrevem episódios de conflito com comunidades indígenas, como no caso em que o grupo de Costa Pinheiro foi alvo do ataque de uma série de disparos de flecha quando estava embarcado em canoas. Os homens caíram na água, tendo um deles morrido afogado.

Uma descrição geral do rio, pouco esmiuçada, mas que revela sua navegabilidade também é apresentada pelos engenheiros da Comissão. Este apanhado revelava se o rio poderia ser utilizado como caminho, que parte apresentava mais dificuldades, se suas margens eram habitadas ou não, entre outros. A visão mais total do rio permitia o conhecimento, ainda que superficial, do caminho tomado e de como deveria prosseguir uma possível incursão futura.

Desta forma, os relatórios de expedições dos engenheiros da Comissão podem ser caracterizados através da análise do discurso integrador que estava sendo construído, ou seja, do quê e por que eram destacados determinados pontos, como barracões, depósitos de seringa ou cachoeiras. Também os rios, temas das viagens, são um bom exemplo desta escolha: estes, em sua maioria, eram ratificados como os mais importantes da região, descritos com minúcia e de acordo com a possibilidade de seu uso para o transporte. Daí, também, o destaque para lugares onde seriam encontrados barracões, povos indígenas e quedas d'água.

Neste encaminhamento, assevero que estes produtos também eram instrumentos da Comissão demonstrando que os territórios percorridos eram passíveis de serem ocupados, conhecidos e incorporados. Relatórios e trabalhos cartográficos eram resultado das viagens de exploração e foram formas de certificar o próprio discurso político que criou a Comissão: a importância da integração do noroeste do Brasil.

\section{Considerações finais}

A Comissão de Linhas Telegráficas do Mato Grosso ao Amazonas tinha por objetivo integrar o país através da construção de linhas telegráficas. Os espaços nos quais a Comissão trabalhou eram tidos como atrasados, distantes e 
vazios. A região fronteiriça precisava ser integrada através do estabelecimento de uma cultura técnica sobre a natureza. Contudo, a "missão civilizatória" pretendida pelo governo não se realizou. Da mesma forma que a ferrovia MadeiraMamoré, após a crise da borracha, se tornou obsoleta, a linha telegráfica de Rondon já estava ultrapassada mesmo antes do término de sua construção; não demoraria muito para que a linha se convertesse em algo inútil. Para além deste ponto, também cabe destacar que a linha nunca funcionou em sua totalidade devido às constantes interrupções ocasionadas pela má conservação de sua própria estrutura.

Desta forma, devemos pensar na importância do empreendimento para além de sua face mais imediata da efetivação da comunicação. Seus objetivos eram mais amplos e estavam centrados na busca da unidade nacional, no conhecimento das riquezas naturais do país. A ação da CLTEMTA traduzia uma política de Estado que visava à ocupação do território noroeste do Brasil. Esta ocupação se basearia no seu conhecimento, na tentativa de diluição das diferenças culturais, produzindo uma população homogênea, capaz de se reconhecer como parte de uma nação. Embora estes ganhos não tenham sido tão substanciais como o Estado almejava, cabe destacar que alguns trabalhos da Comissão tiveram projeção posterior.

Os trabalhos de abertura de caminhos em meio à floresta serviram como base para 0 traçado da antiga BR 364 e à implantação de projetos de colonização nas décadas de 1940 e 1970 nos atuais estados do Mato Grosso e Rondônia. Além disso, algumas regiões onde havia estações telegráficas se desenvolveram em municípios, como Vilhena, Jy-Paraná e Pimenta Bueno, por exemplo. ${ }^{24}$ A comissão também influenciou diretamente a criação do Serviço de Proteção ao Índio e Localização dos Trabalhadores Nacionais, o SPILTN, no ano de 1910, tendo sido Rondon seu criador e primeiro diretor.

Cabe aqui ressaltar também, quanto a suas dificuldades de realização de objetivos, que o período no qual a Comissão desenvolveu suas atividades foi do apogeu à crise da borracha na região amazônica. Assim, enquanto no começo do empreendimento, esta era uma área de riquezas, que precisava ser desenvolvida para o próprio fomento da economia nacional, nos seus anos finais em campo a crise já se alastrara e o noroeste do Brasil voltava a conviver com a pobreza e migração de investimentos do Estado para outros lugares. A Comissão foi o remanescente do interesse governamental da região.

Especificamente no que diz respeito ao levantamento territorial e aos saberes geográficos produzidos pelos engenheiros militares da Comissão Rondon, eles forneceram uma série de subsídios etnográficos e geográficos para a elaboração do Dicionário Histórico, Geográfico e Etnográfico, preparado pelo Instituto Histórico e Geográfico Brasileiro, 0 IHGB, quando das comemorações do centenário da independência em $1922 .{ }^{25}$ No mesmo período, relatórios, cadernetas e material cartográfico da CLTEMTA, por meio de seu Escritório Central, começaram a ser utilizados para a confecção de uma Carta Geral do Mato Grosso. A demanda pela carta partiu do governo deste estado, e, ainda que tenha ficado pronta apenas em 1952, por ter enfrentado uma série de problemas orçamentários, foi, por décadas, considerada a representação cartográfica mais precisa e completa daquelas regiões.

Assim, como vemos, os produtos da CLTEMTA foram utilizados por muitos anos no estabelecimento de representações cartográficas dos territórios por ela percorridos. Estes produtos posteriores como a Carta Geral do Mato Grosso, por exemplo, demonstram a importância dos saberes geográficos produzidos pelos engenheiros militares da Comissão. Tanto que estes saberes não ficaram restritos ao próprio empreendimento, antes circulavam como um símbolo do conhecimento efetivamente existente sobre as regiões. Exemplo, ainda, de que conhecer e mapear a região noroeste do Brasil não foi um projeto abandonado e esquecido quando da conclusão dos trabaIhos da CLTEMTA em 1915. Foi um ideal perseguido pela República brasileira que parecia ter em seu território sua própria expressão. 
Patricia Marinho Aranha é mestre em História das Ciências e da Saúde pelo Programa de Pós-Graduação em História das Ciências e da Saúde - Casa de Oswaldo Cruz/Fiocruz. E-mail: aranha2909@hotmail.com

1 MACIEL, Laura Antunes. A nação por um fio: caminhos, práticas e imagens da Comissão Rondon. São Paulo: Educ/Fapesp, 1998. MACIEL, Laura Antunes. Cultura e tecnologia: a constituição do serviço telegráfico no Brasil. Revista Brasileira de História, v. 21, n. 41, p. 127-144, 2001

2 SÁ, Dominichi Miranda de; SÁ, Magali Romero; LIMA, Nísia Trindade. Telégrafos e inventário do território no Brasil: as atividades científicas da Comissão Rondon (1907-1915). História, Ciências, Saúde - Manguinhos, Rio de Janeiro, v. 15, 2008. DIACON, Todd A. Rondon: 0 marechal da floresta. São Paulo: Companhia das Letras, 2006. MACIEL, op. cit., 1998.

3 MACIEL, op. cit., 1998, 2001.

$4 \quad$ SÁ et al., op. cit.

5 FIGUEIRÔA, Silvia F. de M. As ciências geológicas no Brasil: uma história social e institucional, 1875-1934. São Paulo: Hucitec, 1997. LOPES, Maria Margareth. 0 Brasil descobre a pesquisa científica: as ciências naturais e os museus no século XIX. São Paulo: Hucitec, 1997.

6 Agradeço ao prof. dr. Sérgio Nunes Pereira pela identificação de três diferentes saberes geográficos construídos no interior da CLTEMTA quando de minha defesa de dissertação de Mestrado. são eles: o relacionado ao inventário do território percorrido, 0 de apoio logístico à construção da linha telegráfica e o representacional. Tratarei de forma mais detalhada a este respeito adiante. 0 próprio conceito de saber geográfico é de sua autoria e se refere ao conhecimento geográfico constituído antes da institucionalização da geografia. ARANHA, Patrícia Marinho. 0 esquadrinhamento do Noroeste do Brasil: 0 saber geográfico e os engenheiros militares da Comissão Rondon (1907-1915). Dissertação (Mestrado em História das Ciências e da Saúde) - Casa de Oswaldo Cruz/Fundação Oswaldo Cruz, 2011. NUNES PEREIRA, Sérgio. Engenheiros e militares e saber geográfico: apontamentos para uma pesquisa. In: Anais do I Encontro Nacional de História do Pensamento Geográfico, Rio Claro, 1999. NUNES PEREIRA, Sérgio. Obsessões geográficas: viagens, conflitos e saberes no âmbito da Sociedade de Geografia do Rio de Janeiro. Revista da Sociedade Brasileira de História da Ciência, v. 3, p. 112-124, 2005.

7 NUNES PEREIRA, op. cit., 1999, 2005.

8 FLORES, Kátia Maia. Caminhos que andam: o rio Tocantins e a navegação fluvial nos sertões do Brasil. Tese (Doutorado em História) -, Universidade Federal de Minas Gerais, Belo Horizonte, 2006.

9 BIGIO, Elias dos Santos. Cândido Rondon: a integração nacional. Rio de Janeiro: Contraponto, 2000.

10 SÁ et al., op. cit.

11 Idem.

12 MACIEL, op. cit., 1998; SÁ et al., op. cit.

13 DEAN, Warren. A luta pela borracha no Brasil: um estudo de história ecológica. São Paulo: Nobel, 1989. DAOU, Ana M. A Belle Époque amazônica. Rio de Janeiro: Jorge Zahar Editor, 2000. [Coleção Descobrindo o Brasil]. DAOU, Ana M. Instrumentos e sinais da civilização: origem, formação e consagração da elite amazonense. História, Ciências, Saúde - Manguinhos, Rio de Janeiro, v. 6, suplemento, 2000. WEINSTEIN, Bárbara. A borracha na Amazônia: expansão e decadência (1850-1920). São Paulo: Hucitec, 1993.

14 LEONARDI, Victor. Os historiadores e os rios: natureza e ruína na Amazônia brasileira. Brasília: Paralelo 15, 1999.

15 CORRÊA, Dora Shellard. Os rios na formação territorial do Brasil. In: ARRUDA, G. (Org.). A natureza dos rios. História, memória e territórios. Curitiba: UFPR, 2008. DUARTE, Rildo Borges. Entre o Sertão e o litoral: telegrafia e geografia nas questões de integração e identidade nacional durante a República Velha (1889-1930). Disponível em: < http://enhpgii.files.wordpress.com/2009/10/rildo-borges-duarte1.pdf > . Acesso em: ago. 2011.

16 CORRÊA, op. cit.

17 Os relatórios referentes à Comissão, bem como os mapas, encontram-se disponíveis no Museu do Índio do Rio de Janeiro; as cadernetas de campo estão arquivadas no Acervo da Reserva Técnica do Museu Histórico do Exército/Forte de Copacabana, também no Rio de Janeiro.

18 FONSECA, Aurélio Cordeiro da; REZENDE, Tatiana Matos. Cadernetas de campo da Comissão Rondon: testemunhos de uma epopeia pelos sertões do Brasil (1900-1930). Rio de Janeiro: Fundação Cultural Exército Brasileiro, 2010.

19 Antonio Pyrineus de Souza nasceu em 25 de agosto de 1879. Fez o curso da Escola Preparatória e Tática do Rio Pardo. Em dezembro de 1901, matriculouse na Escola Militar do Brasil e, em dezembro de 1907, foi colocado, pelo Ministério da Guerra, à disposição da CLTEMTA. Em dezembro de 1909, foi nomeado para dirigir a nova turma de exploração do rio Jaru, com o objetivo de executar o levantamento expedito deste rio empregando uma bússola e um relógio. Em dezembro de 1912, pediu exoneração da CLTEMTA. Foi bastante elogiado por Rondon quando da ocasião de sua exoneração. Participou também do reconhecimento do Juruena ao Madeira. Em novembro de 1913, apresentou-se ao 5 Batalhão de Engenharia vindo da Comissão. Em 1914 , apresentou-se ao Escritório Central da Comissão, no Rio de Janeiro. Foi nomeado para servir na expedição Roosevelt-Rondon como chefe da turma auxiliar que deveria subir o rio Amazonas ao encontro da expedição principal. Em maio de 1914, voltou ao Escritório Central da Comissão e, em junho de 1914 , foi desligado da Comissão, voltando a ela em dezembro deste mesmo ano para executar o levantamento expedito dos rios Paranatinga e São Manoel, desde suas cabeceiras até a foz no rio Tapajós. Depois desta expedição, trabalhou no Escritório Central fazendo croquis das áreas percorridas. Seguiu com carreira militar como adido do $5^{\circ}$ Batalhão de Engenharia em virtude de ordem telegráfica do próprio Rondon. Reformou-se como coronel e faleceu em 17 de fevereiro de 1936

Amarante nasceu em 31 de dezembro de 1880. Estudou no Colégio Militar entre os anos de 1894 e 1901, sendo nomeado praça em 8 de março de 1901. Estudou na Escola Militar do Brasil entre 1901 e 1904 e complementou seus estudos na Escola de Artilharia e Engenharia em 1906. Esteve na Comissão entre 20 de fevereiro de 1907 e 16 de março de 1914. Depois, serviu na Comissão do Ministério da Guerra na Europa, de 22 de abril a outubro de 1914. Após a guerra, foi lotado no 5 Batalhão de Engenharia (à disposição da CLTEMTA de 30 de dezembro de 1905 a 7 de agosto de 1929). Participou do curso de aperfeiçoamento de oficiais em 1920 e de Estado-Maior. Foi promovido a major em 9 de fevereiro de 1923, sendo o principal responsável por pique, levantamento regular e nivelamento do eixo da linha, após o levantamento Burity-Juruena. Trabalhou na CLTEMTA e no Escritório Central durante toda a 
vida. Morreu de febre tifoide que adquiriu em serviço, no dia 7 de agosto de 1929 em Santo Antônio do Madeira, Mato Grosso, como chefe do $3^{\circ}$ Distrito Telegráfico e Estratégico do Mato-Grosso ao Amazonas.

Costa Pinheiro nasceu em 5 de março de 1872. Em 1907, saiu para o estado do Mato-Grosso para servir como inspetor de $2^{\text {a }}$ classe na Comissão. Em maio deste mesmo ano, chegou a Cuiabá e iniciou levantamento e locação da linha tronco. Fez nivelamento de eixo da linha até agosto de 1909, e, neste mesmo mês iniciou os trabalhos de exploração do rio Jacy-Paraná desde a sua foz, no rio Madeira. Em janeiro de 1910, retornou ao Rio de Janeiro. Em março deste mesmo ano, apresentou-se ao Escritório Central, e, no mês de junho, entregou relatório de seus serviços e foi dispensado, a seu pedido, de seu cargo de ajudante na CLTEMTA. Recolheu-se ao $5^{\circ}$ Regimento de Artilharia montado em Aquidauana, no Mato Grosso - atualmente este município pertence ao estado de Mato Grosso do Sul. Em junho de 1911, o Ministério da Guerra o colocou à disposição da CLTEMTA que o nomeou como inspetor de $1^{\text {a }}$ classe ficando adido do Escritório Central da Comissão. Em novembro, foi nomeado para chefiar a turma da expedição Juruena-Tapajós e, no dia 15 deste mês, partiu para o Juruena. Seguiu na carreira tendo se reformado como major. Todas as informações biográficas aqui apresentadas acerca destes engenheiros militares se encontram em suas respectivas fés de ofício, arquivadas no Palácio Duque de Caxias, Rio de Janeiro.

200 rio Jaru (atualmente chamado de Jauru) está localizado no atual estado do Mato Grosso. Com nascente na Chapada dos Parecis, próximo à nascente do Juruena, desemboca na margem direita do rio Paraguai, já na área do Pantanal. 0 rio Juruena é um afluente do Amazonas, com nascente localizada na Serra dos Parecis, no atual estado do Mato Grosso, a noroeste de sua capital, Cuiabá. Seu nome é Juruena até a confluência com o rio Teles Pires, quando passa a se chamar Tapajós e desemboca no rio Amazonas, na região de Santarém, no Pará. Os rios Papagaio e Burity são afluentes do Juruena - em certa altura, o Juruena forma um delta onde desembocam diversos rios, entre eles o Burity, Papagaio, Utiauiná e Formiga, que foram rios percorridos nesta expedição de Amarante. 0 rio Jacy-Paraná é um dos afluentes do rio Madeira, estando situado no atual estado de Rondônia, próximo à atual capital, Porto Velho - antiga região da cidade de Santo Antônio do Madeira. Atualmente, este rio possui relativa importância para aquela região, consistindo numa via de penetração para o interior.

21 AMARANTE, Emmanuel Silvestre do. Levantamento e locação do trecho comprehendido entre os rios Zolaharuiná (Burity) e Juruena. Commissão de Linhas Telegraphicas Estrategicas de Matto Grosso ao Amazonas, Publicação 6, Anexo 3. Rio de Janeiro: Papelaria Luiz Macedo, 1910. PINHEIRO, Manoel Theophilo da Costa. Exploração do rio Jacy-Paraná. Commissão de Linhas Telegraphicas Estrategicas de Matto Grosso ao Amazonas, Publicação 5, Anexo 2. Rio de Janeiro: Papelaria Luiz Macedo, 1910. SOUZA, Antonio Pyrineus de. Levantamento expedito do rio Jaru. Commissão de Linhas Telegraphicas Estrategicas de Matto Grosso ao Amazonas, Publicação 25. Rio de Janeiro: Papelaria Luiz Macedo, 1910.

22 PINHEIRO, Manoel Theophilo da Costa. Exploração do rio Jacy-Paraná. Commissão de Linhas Telegraphicas Estrategicas de Matto Grosso ao Amazonas, Publicação 5, Anexo 2. Rio de Janeiro: Papelaria Luiz Macedo, 1910, pág. 5.

23 dem, p. 8.

24 BIGIO, op. cit.

25 BERNARDINO, M. G. A. Cartografia na Comissão Rondon: redesenhando o Mato Grosso e regiões circunvizinhas. In: $3^{\circ}$ Simpósio Ibero-americano de História da Cartografia. Agendas para a História da Cartografia Ibero-americana, 2010. São Paulo, 2010. 